\title{
La Niña events before and after 1979 and their impact in southeastern South America during austral summer: role of the Indian Ocean
}

\author{
Gabriel Cazes-Boezio $^{1, *}{ }^{,}$Stefanie Talento ${ }^{1,2}$ \\ ${ }^{1}$ Universidad de la República, Instituto de Mecánica de los Fluidos e Ingeniería Ambiental, Facultad de Ingeniería, \\ Julio Herrerra y Reissig 565, Montevideo, Uruguay \\ ${ }^{2}$ Universidad de la República, Instituto de Física, Facultad de Ciencias, Iguá 4225, Montevideo, Uruguay
}

\begin{abstract}
In this study, we analyzed the influence of interannual variability in sea surface temperature (SST) on the climate of southeastern South America (SESA) during austral summer. We found that the correlation between the El Niño Southern Oscillation (ENSO) and rainfall over southern Brazil-northern Uruguay (SB-NU) was not statistically significant between 1949 and 1978, but it was significant between 1979 and 2009. The results show that this change in correlation was largely due to the modified rainfall response over SB-NU to La Niña events. A cluster analysis for all summers between 1949 and 2009 identified a turning point of La Niña events in 1979. We document the atmospheric circulation patterns associated with the strong correlation between ENSO and the rainfall over SB-NU after 1979 and hypothesize causes of the weaker correlation in the earlier period. In particular, numerical simulations produced using the UCLA atmospheric general circulation model showed important differences between upper tropospheric circulation patterns during ENSO cold episodes after the late 1970s relative to the earlier period. Such differences were consistent with changes in the impacts of La Niña events on SESA. The differences in Indian Ocean SST anomalies largely explained these results.
\end{abstract}

KEY WORDS: La Niña $\cdot$ Southeastern South America $\cdot 1970$ s change $\cdot$ SST anomalies $\cdot$ ENSO

\section{INTRODUCTION}

Several studies have documented the effects of El Niño Southern Oscillation (ENSO) on the climate of southeastern South America (SESA) (Ropelewski \& Halpert 1987, 1989, Aceituno 1988, 1989, Pisciottano et al. 1994, Grimm et al. 1998, 2000, Grimm 2003, Cazes-Boezio et al. 2003, Kayano et al. 2009, Silva et al. 2009, Zamboni et al. 2010). Some of these studies found statistically significant effects in the austral spring of ENSO years and somewhat weaker effects during the austral autumn of the subsequent years, with a tendency for positive precipitation anomalies over SESA during El Niño and negative anomalies during La Niña (Pisciottano et al. 1994, Grimm et al.

${ }^{*}$ Corresponding author: agcm@fing.edu.uy
1998, 2000). However, several of these studies failed to find a clear connection between La Niña and the climate of most of SESA during austral summer.

Many of these studies used precipitation time series that ended in the 1980s or mid-1990s. In contrast, Kayano et al. (2009) analyzed the interannual relationships between South American precipitation and sea surface temperature (SST) indices in 2 periods: 1948-1976 and 1977-2002. The authors found the most pronounced differences between these periods in an area centered at $10^{\circ} \mathrm{S}$ and $50^{\circ} \mathrm{W}$ in southern Brazil and Uruguay. In this, the positive (negative) relationship between El Niño (La Niña) and precipitation was stronger in the later period. 
The physical processes that can affect the interannual climatic variability of SESA, whether related to ENSO or not, have also been studied to a considerable extent. Studies have investigated regional anomalies of atmospheric circulation (Robertson Mechoso 2000), the effects of low-level circulation (NoguésPaegle \& Mo 1997, Salio et al. 2002, Liebmann et al. 2004, Silva et al. 2009), the effects of soil conditions in regions close to SESA (Grimm 2003, Grimm et al. 2007, Grimm \& Zilli 2009), changes in the onset and duration of the monsoon season during long-term periods (Carvalho et al. 2011), and the influence of SST anomalies in oceans other than the Pacific.

The effects of SST anomalies in the Atlantic Ocean on the climate variability of the Southern Atlantic Convergence Zone (SACZ) and SESA were studied by Barreiro et al. (2002, 2005), Robertson et al. (2003), and Barreiro \& Tippmann (2008). Barreiro et al. $(2002,2005)$ used ensembles of numerical simulations forced with observed global SST and focused on the January-FebruaryMarch season. In these works, the authors found local responses of the atmosphere to SST anomalies over the tropical South Atlantic that primarily affect the SACZ over the ocean. These responses occur on interannual and decadal time scales. Robertson et al. (2003) also performed numerical simulations forced with different types of SST anomalous patterns in the tropical South Atlantic. When they considered basin-wide patterns obtained through empirical orthogonal function analysis, the general circulation model response resembled the observed covarying circulation pattern at low levels in the SACZ. They also considered a local SST negative anomaly centered at approximately $20^{\circ} \mathrm{S}$ and $30^{\circ} \mathrm{W}$, and found a dipole-like response over the SACZ and the northern part of SESA. This response implies negative anomalies of precipitation in the SACZ and positive anomalies north of SESA. Because this type of cold anomaly tends to occur when the SACZ is intensified, as discussed by Kalnay et al. (1986). The variability of the SACZ is influenced more strongly by the basin-scale SST variability than by the underlying ocean. Barreiro \& Tippmann (2008) studied the effect of SST anomalies in the Atlantic Ocean on precipitation over SESA during January and February. With the presence of warm anomalies in the equatorial Atlantic, the influence of ENSO warm episodes is weaker than in the absence of these anomalies, which suggests that the Atlantic Ocean SST anomalies can modulate the influence of ENSO on SESA, at least during the warm episodes.
The effects of SST anomalies in the Indian Ocean on South America have also been studied in considerable detail. Chan et al. (2008) studied the effect of the Indian Ocean Dipole (IOD) SST anomalous pattern (Saji et al. 2005) on rainfall in South America. The authors used data from the National Center for Environmental Prediction - National Center for Atmospheric Research (NCAR-NCEP) for atmospheric circulation and from the Hadley Centre for SST, and focused on the September-October-November season from 1958 to 1999 . They found that during this season, positive phases of the IOD tend to be associated with positive anomalies of precipitation at the subtropical La Plata basin and with negative anomalies at the SACZ. This connection is associated with wave-train-like teleconnection along a great circle between the Indian Ocean and South America, and with a low level anticyclonic anomaly off the coast of Brazil. Drumond \& Ambrizzi (2008) focused on the December-January-February (DJF) season, and used the analysis of observations as well as numerical simulations. They found a pattern of positive SST anomalies east of Africa tended to be associated with dry conditions over the SACZ and enhanced precipitation over sub-tropical South America. The simulated atmospheric circulation indicated an austral extra-tropical wave perturbation emanating from the Indian Ocean that follows an arc-like trajectory through the extra-tropics. A second SST variability mode was located in the western Pacific Ocean that also associates warm SST anomalies with dry conditions over the SACZ and enhanced precipitation over sub-tropical South America. This connection may be associated with the propagation of an anomalous wave train emanating from Indonesia, similar to the PSA 2 teleconnection pattern (Mo \& Ghil 1987). Taschetto \& Ambrizzi (2012) studied the effect on South America of basinwide warming over the Indian Ocean. The authors found significant correlations between this pattern and the precipitation at the La Plata basin during austral fall (March-April-May season).

The present study focuses on a region of SESA that includes part of southern Brazil and northern Uruguay (SB-NU). In this region, the influence of La Niña episodes during austral summer (DJF) has been stronger after the late 1970s, which helps to explain the increase in correlation between the ENSO indexes and local precipitation during this season. Considering this, the present study addresses the relationship between La Niña episodes and the climate of this region during austral summer, distinguishing 2 periods: 1949-1978 and 1979-2009. Note 
that although SB-NU (defined in Section 3) is a rather small region, it includes the basins of the Uruguay and Negro Rivers, which have several hydropower dams that are important as energetic resources for the countries in the region. Moreover, this is a very productive region in terms of agriculture, including crops that are produced during austral summer.

The availability of atmospheric and oceanic data for these periods imposes a difficulty: the rawinsondes of the atmospheric observational network were relatively more abundant during the later period compared with the earlier (as shown in Section 2). In addition, satellite observations related to atmospheric circulation and SST are available for most of the later period but not for the earlier. If our only interest was studying the connection of La Niña episodes with the region of interest during the later period, a study based purely on the analysis of observations might be quite useful. However, if we are interested in comparing the earlier and later periods, the shortcomings of the data with respect to their observational basis make it necessary to rely fundamentally on numerical simulations with prescribed SST. Such simulations can be useful at least to propose hypotheses regarding the physical processes involved in the long-term variability of the connection. In addition, it is preferable to consider an SST data set that does not assimilate satellite observations because the data that include this type of observation might be biased with respect to the data from periods that do not include them.

In Section 2, we detail the databases used, the principal characteristics of the numerical model employed, and the simulations. In Section 3, we analyze the tropical SST anomaly patterns associated with La Niña events, as well as the variation of these patterns in the 2 periods of interest. In Section 4, we investigate the physical processes associated with the connection between La Niña and the SB-NU climate, using observations and model simulations. Finally, we present the discussion and conclusions in Section 5.

\section{DATASET AND SIMULATIONS}

To characterize the precipitation over South America, we used the precipitation data analysis PREC/L from the National Oceanic and Atmospheric Administration (NOAA) (Chen et al. 2002). This data set is based on gauge observations and extends from January 1948 to the present. The gridded data, which are not available over oceans, have a $2.5^{\circ}$ horizontal resolution.
To examine anomalies of precipitation and atmospheric circulation during the cold episodes that occurred after 1979, we used the precipitation data from the Climate Prediction Center Merged Analysis of Precipitation (CMAP) (Xie \& Arkin 1997) and the reanalysis from the NCEP-NCAR described by Kalnay et al. (1996). The CMAP includes precipitation estimates over the oceans based on satellite observations, and is only available from 1979 to the present. The NCEP-NCAR reanalysis is available from 1948 to the present, but its observational basis in most of the Southern Hemisphere ( $\mathrm{SH}$ ) is very weak, at least during the first 2 decades. Fig. 1a shows the location of all operating rawinsondes in the SH between 1951 and 1967 (from Oort 1983). Only 2 rawinsondes were deployed between the date line and South America. There was a significant increase in rawinsondes in the southern Pacific basin and South America after 1970 (Fig. 1b), and the data set also assimilates observations from satellites after the late 1970s. This evolution of the observational network may introduce bias between sub-periods of the data set.

Model simulations were performed using the UCLA atmospheric general circulation model (AGCM) with a horizontal resolution of $2^{\circ}$ (latitude) by $2.5^{\circ}$ (longitude) and 29 vertical layers. The main features and parameterizations of the physical processes at the sub-grid scale are described by Farrara et al. (2000) and Konor et al. (2009). We performed several numerical experiments by prescribing different SST fields for specific purposes, as described in Section 4. All prescribed boundary conditions in the AGCM have monthly variations; the model deduces the daily variability using the procedure of Farrara et al. (2000). Each experiment consists of a 9-member ensemble (differing only in the initial conditions), and the simulated period is 1 November through 28 February in every case. For each experiment and variable of interest, we calculated the DJF ensemble mean.

The SST data set used was the ERSST v2 from NOAA (Reynolds et al. 2002). This data set only assimilates the in situ observations available in the ICOADS database. Satellite observations are used to compute the empirical modes of the high-frequency SST variability used to define the algorithm for optimal interpolation, but are not directly assimilated to avoid bias between periods before and after the introduction of this type of observation. This data set is used to compute the N34 index (Section 3), to study changes in the anomalous SST patterns of La Niña episodes before and after the late 1970s, and to 

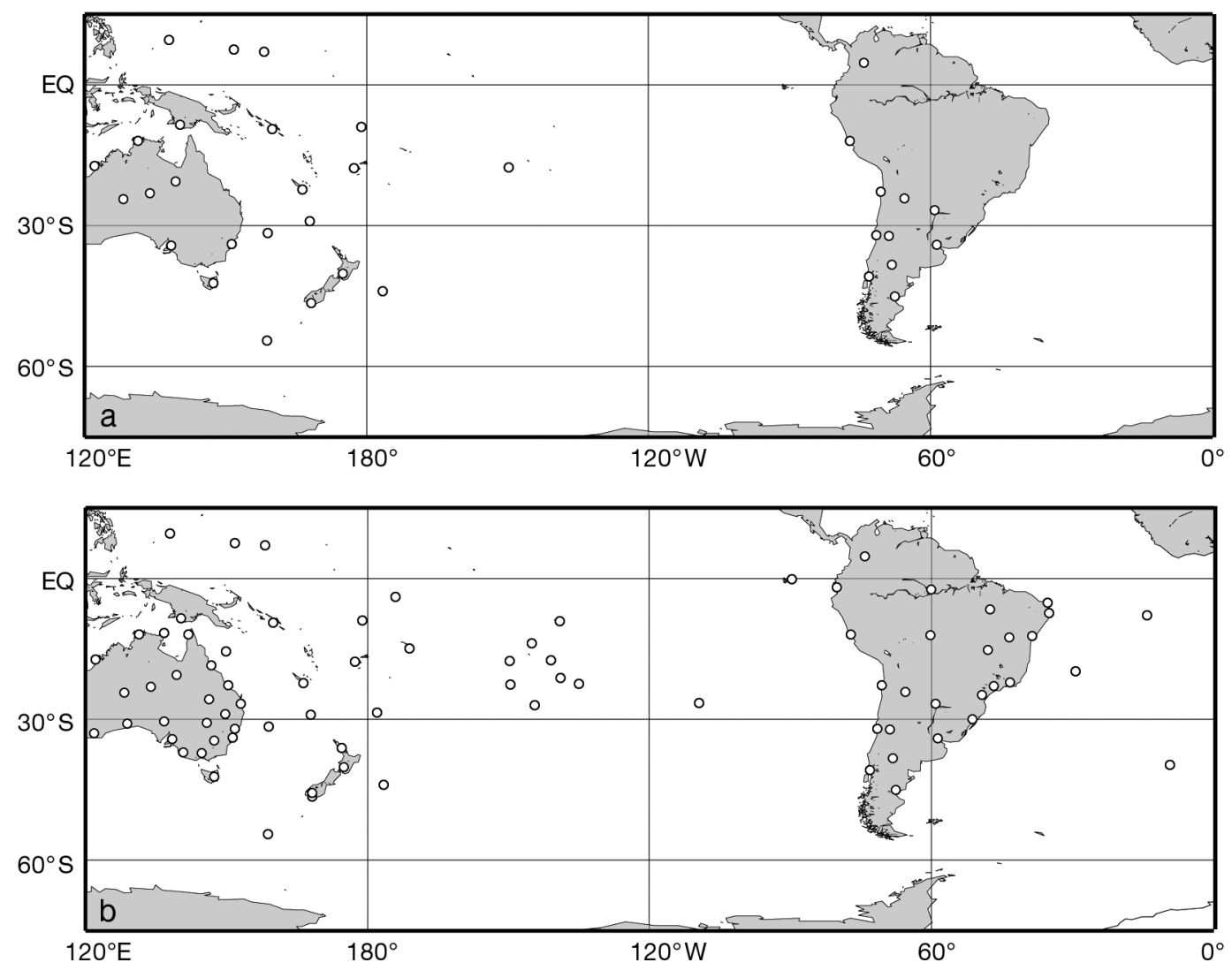

Fig. 1. Rawinsondes in the South Pacific and South America in operation during the periods (a) $1957-1966$ and (b) 1967 to present. Elaborated from information given by Oort (1983)

compute the SST fields prescribed to the AGCM simulations. The data set includes the surface temperature at sea areas covered by ice.

\section{SST ANOMALIES DURING LA NIÑA EVENTS}

To further investigate the changes in correlation between ENSO indexes and precipitation in SESA during summer reported by Kayano et al. (2008), we computed the correlation between the N3.4 index in DJF (defined as the average SST in the area enclosed by $5^{\circ} \mathrm{S}, 5^{\circ} \mathrm{N}, 170^{\circ} \mathrm{W}$ and $120^{\circ} \mathrm{W}$ ) and the simultaneous precipitation over South America (according to PREC/L data) for 2 periods: 1948-1978 and 19792009. These periods split the data from the late 1940s to the present into halves. Each DJF season was labeled by the year corresponding to January and February. Fig. 2 shows the correlations for the seasons in the periods 1949-1978 (Fig. 2a) and 1979-2009 (Fig. 2b). In the latter group, we excluded DJF of 1998 because this case had extreme (positive) anomalies in both N3.4 and precipitation over northern SESA, generating an increase in the correlation in this region that may not be representative of the entire population. Areas of statistical significance at a $95 \%$ confidence level are shaded (the significance was computed according to a Student's $t$-test with 30 degrees of freedom). The correlation between N3.4 and precipitation over northern SESA is statistically significant for the period 1979-2009 but not for 1949-1978. Hereafter, we focus on this region, defined between 32 and $25^{\circ} \mathrm{S}$ and between 58 and $50^{\circ} \mathrm{W}$ (i.e. the Atlantic coast). Because it covers southern Brazil and northern Uruguay, we designate it as 'SB-NU.'

Fig. 2c,d shows scatter plots of N3.4 during DJF versus the simultaneous precipitation averaged over SBNU for the periods 1949-1978 and 1979-2009. There is a strong difference between these periods in terms of the response in cases with colder N3.4 values. There is a tendency in the later period for below-average precipitation, but this is not evident in the earlier period. More precisely, if we choose a value of $-0.7^{\circ} \mathrm{C}$ for the N3.4 index, we find that all DJF seasons after 1979 with N3.4 anomalies lower than this value register negative precipitation anomalies in SB-NU. This is not the case for similar seasons before 1979. This feature contributes significantly to the correlation in- 

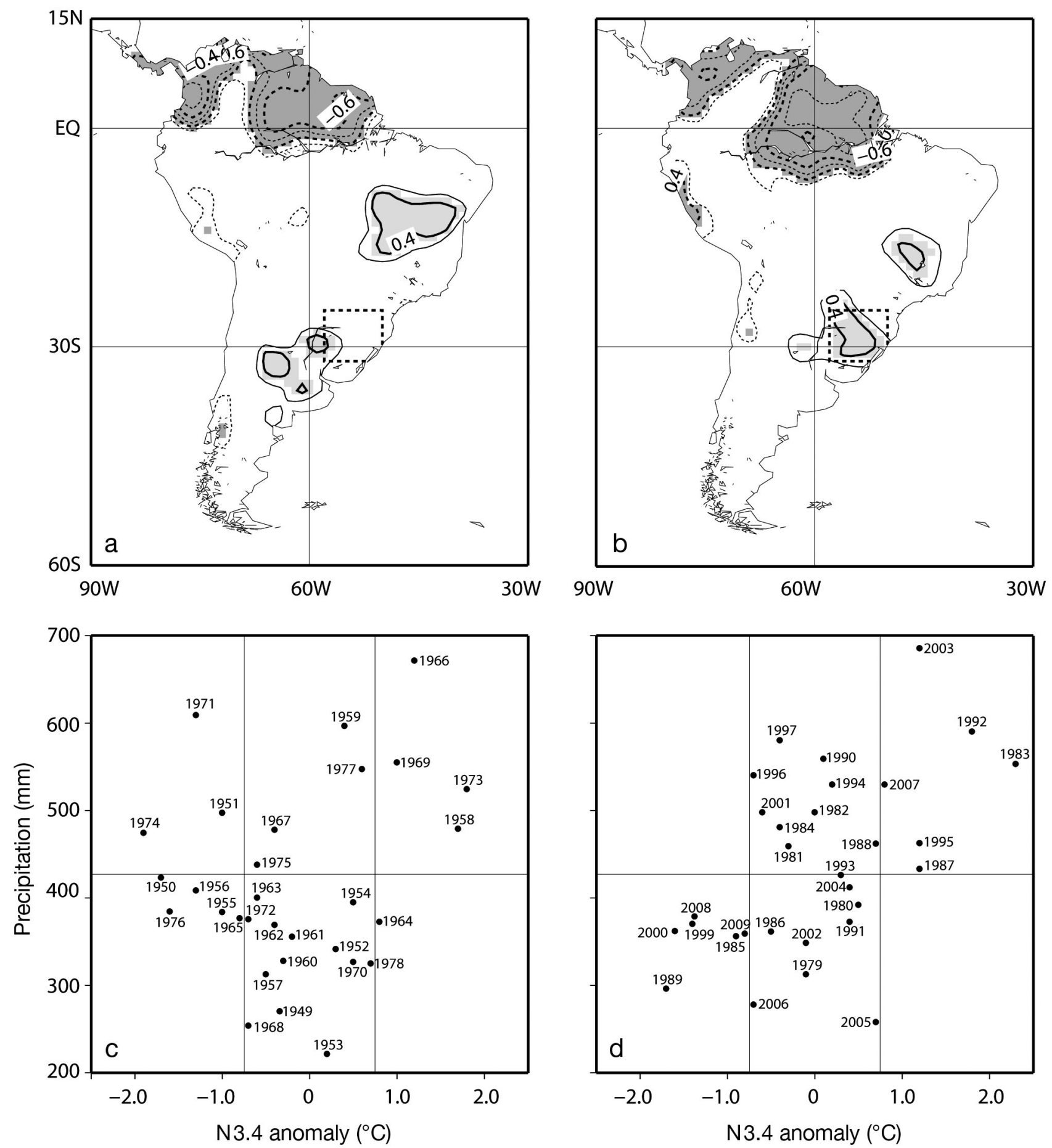

Fig. 2. (a) Correlation between N3.4 and simultaneous precipitation in DJF over South America for the period 1949-1978. The box indicates southern Brazil-northern Uruguay (SB-NU). Areas statistically significant at the $95 \%$ level are shaded. Negative contours are dotted or dashed, and contours between -0.2 and 0.2 are omitted; the contour interval is 0.1 . (b) As in panel a, but for the period 1979-2009, excluding 1998. (c) N3.4 anomaly versus average precipitation in SB-NU in DJF for the period 1949-1978. The 1949-2009 average precipitation and $\pm 0.7^{\circ} \mathrm{C}$ N3.4 anomalies are shown. (d) As in panel c, but for the period 
Table 1. La Niña events according to the criterion of an N3.4 anomaly below $-0.7^{\circ} \mathrm{C}$ in $\mathrm{DJF}$

\begin{tabular}{|lc|}
\hline Pre 1979 & Post 1979 \\
\hline 1950 & 1985 \\
1951 & 1989 \\
1955 & 1999 \\
1956 & 2000 \\
1965 & 2008 \\
1971 & 2009 \\
1974 & \\
1976 & \\
\hline
\end{tabular}

crease. If we exclude seasons with N3.4 lower than $-0.7^{\circ} \mathrm{C}$ during $1949-1978$, the correlation between the index and SB-NU precipitation increases from 0.20 to 0.53. If we do the same for seasons during 1979-2009, the correlation drops from 0.49 to 0.34 . Considering the impact of the cases with $\mathrm{N} 34$ below the $-0.7^{\circ} \mathrm{C}$ threshold on the correlation between N4.3 and precipitation over NB-SU, we define La Niña events, for the purposes of this work, as all DJF seasons with an N3.4 index below $-0.7^{\circ} \mathrm{C}$. These seasons are listed in Table 1 and are labeled below as 'pre79' or 'post79' La Niña events according to their occurrence before or after 1979. There are other possible definitions that consider anomalies of oceanic or atmospheric indexes over longer periods (Trenberth 1997). Such definitions can be useful to study the global impacts of ENSO over an entire year. They produce sets of La Niña cases similar but not identical to that of Table 1. The definition preferred in the current work was chosen because it has a direct relationship with the simultaneous correlations analyzed in Fig. 2.

The maps of the SST anomalies for the post79 and pre79 La Niña events and their differences are shown in Fig. 3a-c. In every panel, the shaded regions show where the anomalies are statistically significant at the $95 \%$ confidence level according to a Monte Carlo test described as follows. For panel (a) (6 post79 La Niña events), we randomly selected 6 elements from the set composed of all DJF periods during 19492009 and computed the 6-element composite DJF SST anomaly (with respect to the 1949-2009 DJF climatology). We repeated this procedure 1000 times. At each grid point, a positive (negative) value of the post79 anomaly is statistically significant at the 95\% confidence level if it is higher (lower) than the composite anomalies in at least $97.5 \%$ of the cases in the sample of 1000 random choices.

For panel (b) (8 pre79 La Niña events), we followed the same procedure but randomly selected 8 elements instead of 6. For panel (c) (difference between the 6 post79 and 8 pre79 La Niña events), we repeated the procedure but randomly selected disjointed sets of 6 and 8 elements and then computed the difference between the composite anomalies.

For the post79 La Niña events at tropical latitudes, we observed negative anomalies in the central Pacific Ocean and warm anomalies in the Indian, Atlantic, and western Pacific Oceans. For the composite of pre79 La Niña events, we also observed cold anomalies in the central Pacific. However, in the Indian, Atlantic, and western Pacific Oceans, the anomalies were all cold. Fig. 3c reveals that the differences between the post79 and pre79 La Niña events can exceed $0.5^{\circ} \mathrm{C}$ in the Indian, eastern Pacific, and Atlantic Oceans.

To confirm the distinction between the La Niña events that occurred before and after 1979 in a manner that does not necessarily involve the SESA climate, we studied the tropical SST anomaly fields using cluster analysis techniques. These techniques group years according to similarities in spatial patterns of the anomalies and have the potential to detect any interdecadal variation. First, we performed a principal component analysis of the region between $10^{\circ} \mathrm{N}$ and $10^{\circ} \mathrm{S}$ and retained the components that explained most of the variability. For this objective, we used the scree-plot criterion (Cattell 1966) which specifies retention of the first 3 components that explained $85 \%$ of the total variance. We then performed cluster analysis, standardizing those 3 principal components to avoid minimizing the importance of the SST anomalies in the Indian and Atlantic basins. Several hierarchical and non-hierarchical cluster analyses were performed using the Euclidean distance in every case. The cluster division depends on the method. However, some aspects of grouping remained unchanged over all techniques. In particular, 4 clusters stood out because their configurations remained very similar across all of the algorithms: Cluster 1 was composed of the years after 1979 with 5 of its 6 components labeled post79 La Niña events, Cluster 2 was composed of pre79 La Niña events, Cluster 3 was composed of the years 1983 and 1998 (events with DJF N3.4 anomalies greater than $2.2^{\circ} \mathrm{C}$ ), and Cluster 4 was composed of years with warm-phase ENSO. The only post79 La Niña event not covered by Cluster 1 occurred in 1985. Fig. 4 shows the results of the complete linkage hierarchical method, indicating the 4 clusters mentioned above.

In summary, all cluster algorithms distinguished the years with warm-phase ENSO and cold-phase ENSO (as expected). Additionally, cold-phase ENSO events before and after 1979 (pre79 and post79 La Niña events) show different anomalous SST patterns, 

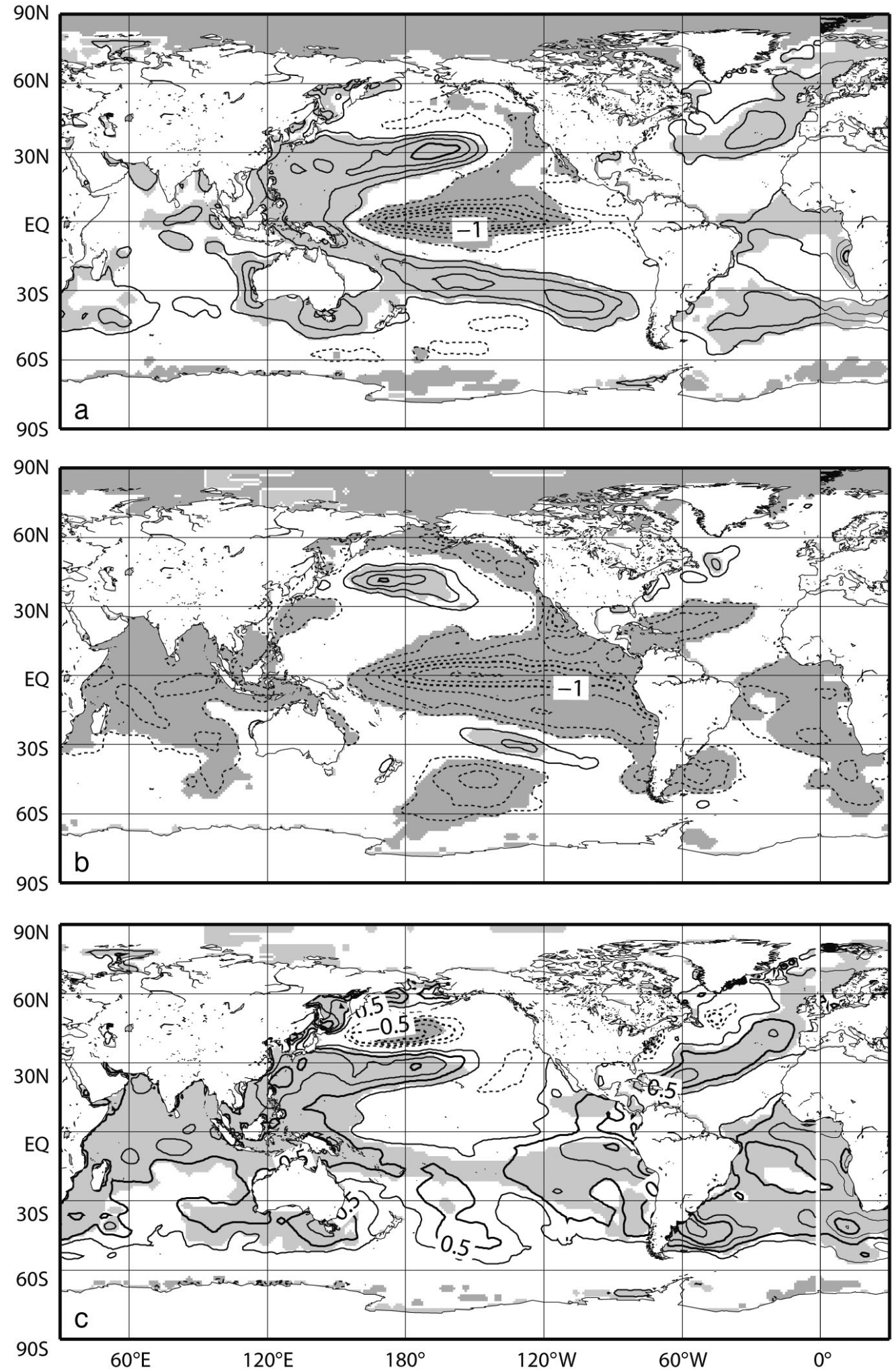

Fig. 3. (a) DJF SST average anomaly for (a) post 1979 and (b) pre 1979 La Niña events (ERSST v2 data). Anomalies are departures from the 1949-2009 mean. Regions where the anomaly is different from 0 at the $95 \%$ level are shaded. The contour interval is $0.5^{\circ} \mathrm{C}$. (c) Difference between the composite shown in panel a and the composite shown in panel b (a minus b). Contour interval: $0.25^{\circ} \mathrm{C}$. Areas statistically significant at the $95 \%$ level are shaded. Negative contours are dashed, and the 0 contour is omitted 


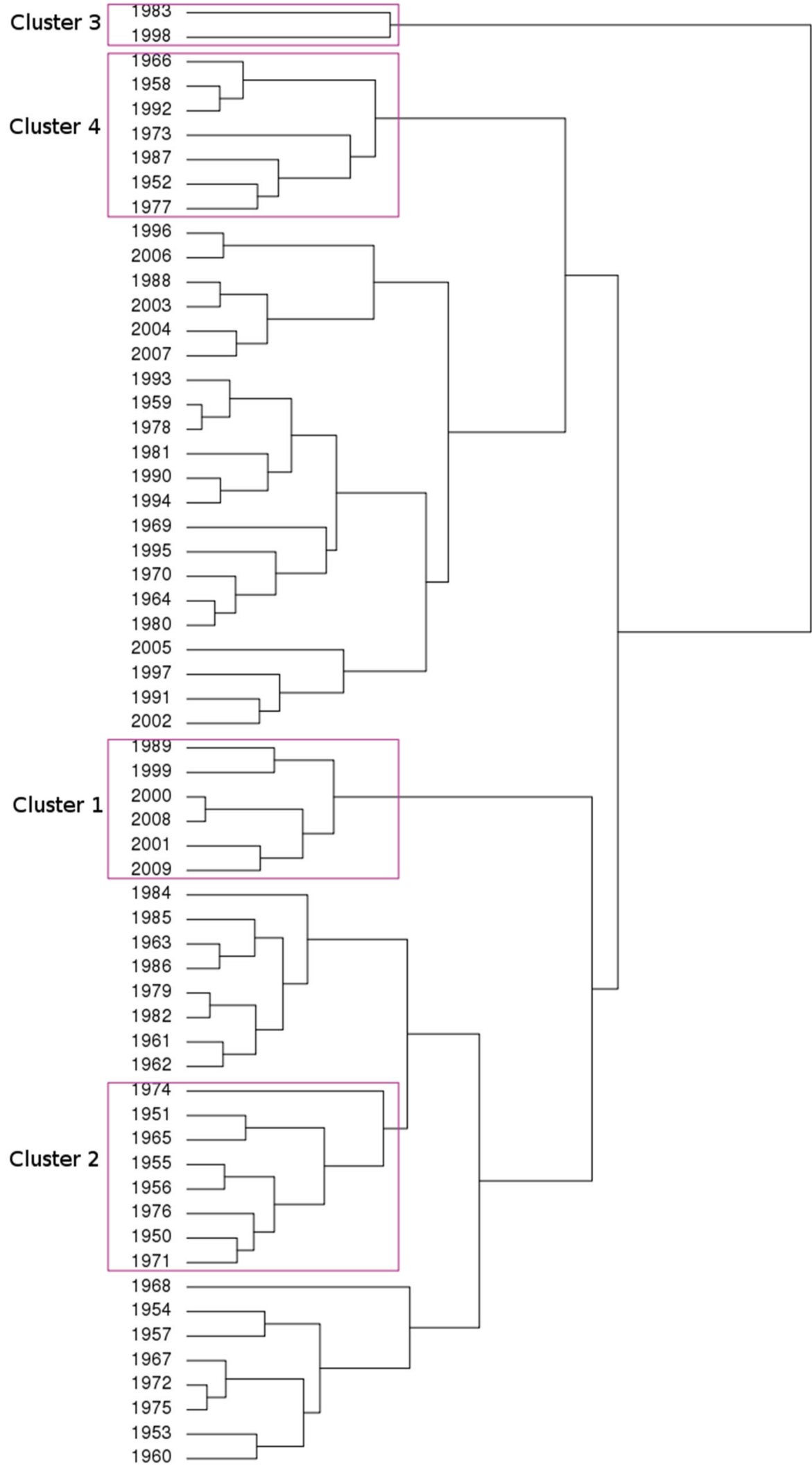

Fig. 4. Dendrogram for the complete linkage clustering method. Only clusters that remain unchanged using several clustering methods are identified which confirms the distinction between the groups of events independently of the SESA climate. Long-term SST variability, including climate shifts and the Pacific Decadal Oscillation (PDO), has been the subject of several studies (e.g. Casey \& Cornillon 2001, Trenberth et al. 2002). Nevertheless, we only focus on the effects of SST variability on SB-NU, rather than on the reasons for such a non-stationarity of these effects. All La Niña events in the 1979-2009 period occurred after the late 1970s climate shift and corresponded to positive phases of the PDO index. In the study of La Niña events, splitting the 1948-2009 period into pre- and post-1979 periods produces results similar to splitting the period into pre- and post-1977 periods (as in Kayano et al. 2009) because no cold ENSO episodes occurred during the late 1970s.

\section{PHYSICAL PROCESSES ASSOCIATED WITH THE LINK BETWEEN LA NIÑA AND SB-NU CLIMATE}

In this section, we describe the atmospheric patterns during cold ENSO episodes that occurred after 1979 and could be relevant to the stronger link between post79 La Niña events and the tendency towards below-average precipitation in SB-NU. We also propose possible causes for the lack of such a linkage during the pre79 La Niña events. We studied both observations and idealized simulations from the UCLA AGCM. The post79 La Niña events occurred in a period of abundant upper-level observations in the $\mathrm{SH}_{\text {; }}$ satellite observations were available for this period. In contrast, the first decades of 1948-1978 (with several La Niña events) had very few upper-level observations in the $\mathrm{SH}$. Thus, cold ENSO events during this period were studied using only model simulations. 


\subsection{Post 1979 La Niña events - observations and model simulations}

The anomalous atmospheric patterns involved in the connection between La Niña and the SB-NU climate may be related to teleconnections and regional processes. Tropical precipitation anomalies have the potential to cause upper-level divergence anomalies that provoke remote influences. Typically, these teleconnections are studied through the analysis of upper-level atmospheric circulation fields. In contrast, analysis of low-level atmospheric circulation fields is essential for studying regional processes. In SESA, low-level meridional wind is particularly important because of its association with moisture fluxes; northerly meridional wind (from the Amazon Basin) increases moisture availability in SB-NU (Nogués-Paegle \& Mo 1997, Grimm et al. 2000, Salio et al. 2002, Silva et al. 2009, Zamboni et al. 2010).

In Fig. 5, we show precipitation anomalies (according to the CMAP analysis), the $200 \mathrm{hPa}$ stream function (according to the NCEP-NCAR reanalysis), and the $850 \mathrm{hPa}$ meridional wind (also from the NCEPNCAR reanalysis) for the composite of the post79 La Niña events. All of the anomalies were calculated by considering departures from the 1979-2009 DJF means. In every case, the areas with statistical significance at the $95 \%$ confidence level are shaded (according to a Monte Carlo test analogous to the one described earlier). Regarding the $200 \mathrm{hPa}$ stream function anomaly, the shaded areas represent where the $200 \mathrm{hPa}$ relative vorticity anomaly is statistically significant at the $95 \%$ confidence level.

For precipitation (Fig. 5a), in addition to the previously mentioned negative anomalies over SB-NU, negative anomalies occur over the central tropical Pacific, and positive anomalies occur over the western tropical Pacific, the South Pacific Convergence Zone (SPCZ), northern South America, and the SACZ; all values are statistically significant at the $95 \%$ level.

Regarding the $200 \mathrm{hPa}$ circulation (Fig. 5b), at tropical latitudes, we find well-documented ENSO patterns, correspondent to its cold phase (Wang 2004): nearly symmetric cyclonic anomalies on both sides of the equator in the Pacific, westerly anomalies over the central equatorial Pacific, and opposite anomalies over the equatorial Atlantic. Additionally, weak westerlies occur over most of the subtropical South Pacific, from Australia to western South America. Over SESA, a cyclonic vorticity anomaly was centered at $30^{\circ} \mathrm{S}$ between SESA and the SACZ.

Robertson \& Mechoso (2000) found that the principal mode of interannual variability in the atmospheric cir- culation over SESA during DJF is a quasi-barotropically equivalent vortex, either cyclonic or anticyclonic. At $200 \mathrm{hPa}$, the vortex has a zonal wave number of 6 and is centered just south of the SACZ at $30^{\circ} \mathrm{S}$ and $40^{\circ} \mathrm{W}$. In the cyclonic phase, the vertical motion field of this mode exhibits a dipole pattern along the eastern coast of South America: anomalous ascent is located the mean SACZ position, and anomalous descent is located around SESA. The stretching term of the vorticity equation at $200 \mathrm{hPa}$ also shows a SESA-SACZ dipole structure, which helps cancel out the tendency caused by the relative vorticity advection. Thus, the vortex is quasi-stationary, constituting a low-frequency variability mode in the region. The authors also found an $850 \mathrm{hPa}$ cyclonic circulation, which has a shorter zonal length than the upper-level vortex. The lowlevel vortex is associated with northward low-level wind anomalies over SESA that reduce moisture advection to the region and favor a decrease in precipitation, i.e. a positive feedback of the anomalous circulation mode. In the anticyclonic phase, the opposite occurs.

Fig. 5b indicates that during the post79 La Niña events, this mode is favored in the cyclonic phase, which is consistent with the precipitation anomalies shown in Figs. 1 \& 5a. Although the $95 \%$ significance level is attained only at the center of the vortex, a large part of it attains the $90 \%$ significance level (Fig. 6). At $850 \mathrm{hPa}$ (Fig. 5c), significant northward wind anomalies occur over much of the La Plata Basin due to weak moisture transport toward SB-NU. These winds are also consistent with the formation of the vortex mentioned by Robertson \& Mechoso (2000) in the cyclonic phase.

Next, we propose possible linkages between the anomalous patterns. La Niña events are associated with low-level anomalies of convergence in northern South America (Aceituno 1988, Kousky \& Kayano 1994, Poveda \& Mesa 1997, Paegle \& Mo 2002), which can contribute to the low-level northward wind anomalies observed around SESA. Because meridional wind at low levels is directly related to the moisture flux towards SESA, these northward anomalies are consistent with the reduced moisture transport and decreased precipitation over the region. Furthermore, this process can be associated with the summer mode documented by Robertson \& Mechoso (2000). As stated previously, the 3-dimensional structure of this mode helps cancel out the vorticity tendencies due to advection and stretching, making the mode quasistationary. The convergence anomalies at the upper levels above SESA associated with the previously mentioned precipitation anomalies contribute to phaselocking of the cyclonic phase of the mode. 

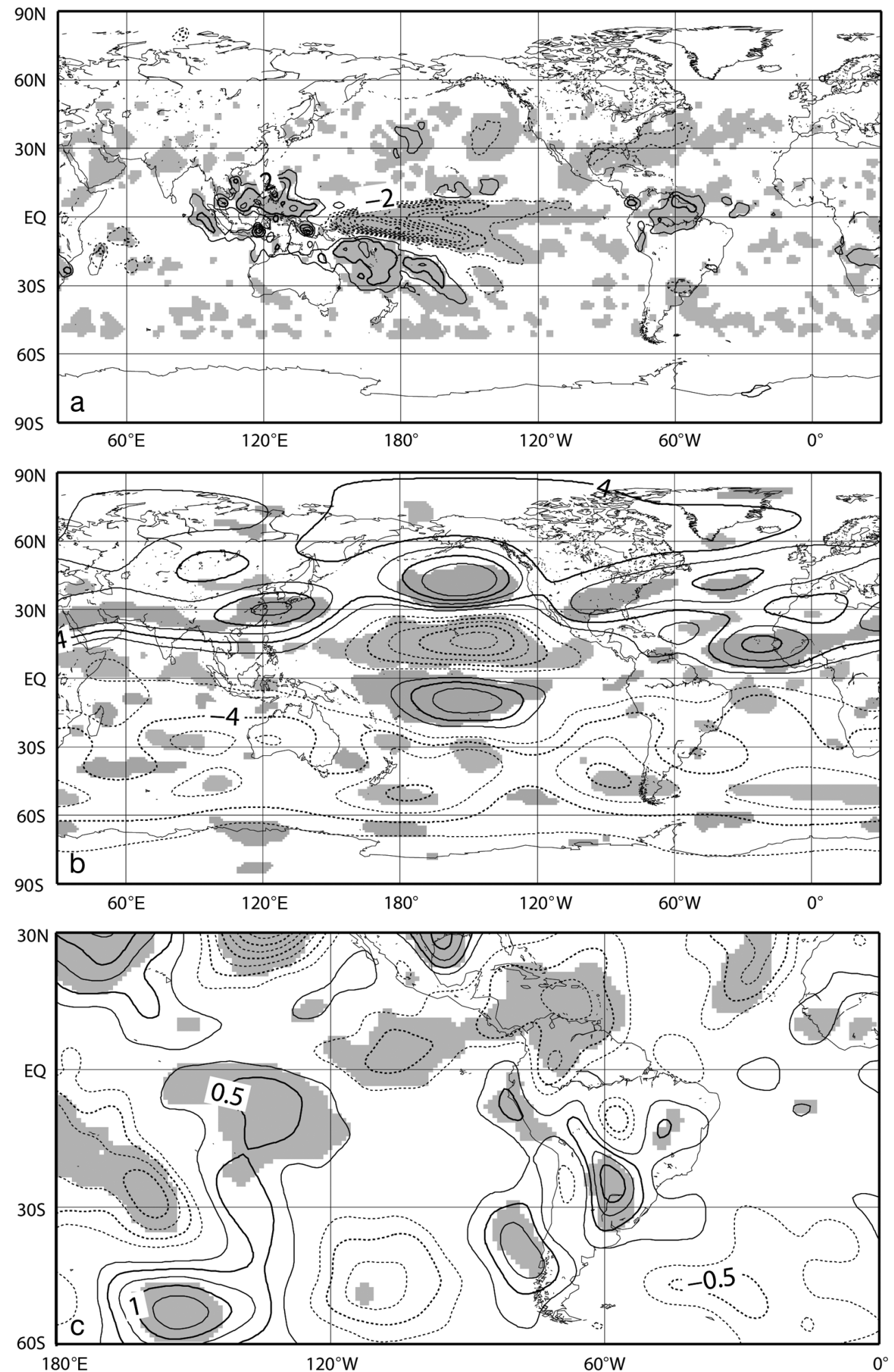

Fig. 5. (a) Post 1979 La Niña event composite of Climate Prediction Center Merged Analysis of Precipitation (CMAP) precipitation anomalies in DJF. The contour interval is $1 \mathrm{~mm} \mathrm{~d}^{-1}$. Anomalies are calculated as departures from the 1979-2009 DJF mean. Areas statistically significant at the $95 \%$ level are shaded. Negative contours are dotted, and the 0 contour is omitted. (b) As in panel a, but for the observed $200 \mathrm{hPa}$ stream function anomalies in DJF; the contour interval is $2 \times 10^{6} \mathrm{~m}^{2} \mathrm{~s}^{-1}$. The dashed lines around South America indicate a region used to compute pattern correlations between this and other anomalous fields, as indicated in Section 4.1. (c) As in panel a, but for observed $850 \mathrm{hPa}$ meridional wind anomalies in DJF; the contour interval is $0.25 \mathrm{~m} \mathrm{~s}^{-1}$ 

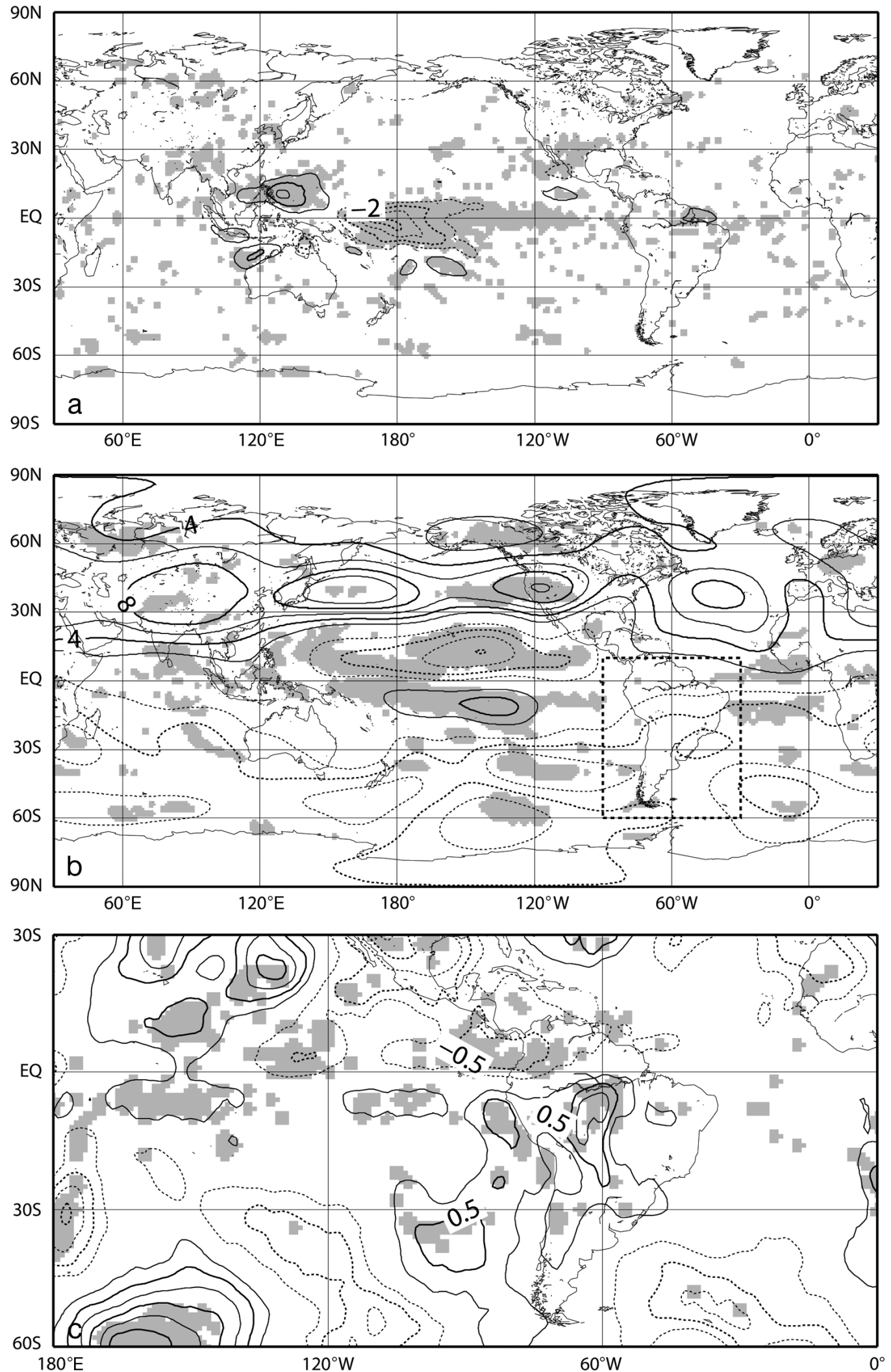

Fig. 6. As in Fig. 5, but for the Global Ocean-Global Atmosphere (GOGA)-post 1979 minus the Control experiments instead of the observed anomalies. In the region around South America between $90^{\circ}-30^{\circ} \mathrm{W}$ and $60^{\circ} \mathrm{S}-10^{\circ} \mathrm{N}$ (dashed lines in Figs. $5 \mathrm{~b} \& 6 \mathrm{~b}$ ), the previously mentioned pattern correlation is 0.87 
In addition to the proposed regional links, the upperlevel divergence anomalies over the tropical oceans (not shown here) could also contribute to the formation of cyclonic upper-level anomalies over SESA through barotropic mechanisms. Sardeshmukh \& Hoskins (1988) studied how rotational wind in the upper troposphere is affected by divergent wind anomalies associated with equatorial divergence sources. The authors used a barotropic model relaxed to the DJF $150 \mathrm{hPa}$ climatology and prescribed an idealized divergence source applied successively at several locations while centered at $5^{\circ} \mathrm{S}$ at various longitudes. In particular, the authors found that various divergence anomalies are able to affect the atmospheric circulation over SESA (see Fig. 7 in Sardeshmukh \& Hoskins 1988). Grimm \& Silva Dias (1995) also studied the SPCZ and SACZ via a barotropic model. Their study revealed an idealized divergence anomaly that represents a southeastward displacement of the SPCZ from its climatological position (which can be associated with 30 to $60 \mathrm{~d}$ oscillations or with cold ENSO episodes), generating an anomalous trough over SESA. The tropical divergence anomalies associated with post79 La Niña events present a more complex structure than those considered in the cited studies. Consequently, these upper-tropospheric teleconnection mechanisms require more specific research.

To evaluate the ability of the UCLA-AGCM to reproduce the observed atmospheric anomalous patterns described above, we performed 2 sets of simulations (experiments) and forced the model with idealized SST fields. The 'Control experiment' was implemented using the 1979-2009 climatological SST, whereas the 'GOGA-post79' experiment (where GOGA means Global Ocean-Global Atmosphere) was performed using the average observed SST of the post79 La Niña events, shown in Fig. 3a. The results obtained from differencing (GOGA-post79 minus Control) represent the simulated atmospheric response to the mean SST anomaly of all post79 La Niña events. The decision to perform simulations with idealized SSTs was based on the lower computational demand compared with simulating each event, which would be the first option. Furthermore, according to the cluster analysis, the SST fields of the cold ENSO episodes can be grouped into post79 or pre79; therefore, using the corresponding means as an idealization of those events is supported by this technique.

Analogous to Fig. 5, Fig. 6 shows the difference between the experiments (GOGA-post79 minus Control) for precipitation, $200 \mathrm{hPa}$ stream function, and $850 \mathrm{hPa}$ meridional wind. Areas statistically significant at the
$95 \%$ level are shaded, similar to Fig. 5. For precipitation (Fig. 6a), the model successfully reproduces the negative anomalies in the central tropical Pacific Ocean and the positive anomalies in the western tropical Pacific and northern South America, albeit with significantly lower magnitudes (by a factor of approximately 1.5). No significant precipitation anomalies occur in either SB-NU or the SACZ. At $200 \mathrm{hPa}$ (Fig. 6b), the simulated anomalies over the Pacific and Atlantic Oceans are similar to those in Fig. 5a. A cyclonic vortex occurs between SESA and the SACZ, similar to the observations (Fig. 5b); however, it does not reach the $95 \%$ statistical significance level. Overall, the simulated anomalies are similar to the observations around South America. One method for measuring this similarity is through pattern correlation analysis (Murphy \& Epstein 1989, Farrara et al. 2000). In the region around South America between $90-30^{\circ} \mathrm{W}$ and $60^{\circ} \mathrm{S}-10^{\circ} \mathrm{N}$ (indicated by the dashed lines in Figs. 5b \& 6b), the previously mentioned pattern correlation is 0.87 . The pattern correlation is also elevated across the entire $\mathrm{SH}$ (for example, the value is 0.85 from the equator to $60^{\circ} \mathrm{S}$ ).

The simulated anomaly of the $850 \mathrm{hPa}$ meridional wind (Fig. 6c) shows positive, statistically significant values in the La Plata Basin, which agrees with the reanalysis data. Nevertheless, the simulated anomalies are weaker than the observations by a factor of $\sim 2$, with a maximum shift towards $10^{\circ} \mathrm{S}$ and $65^{\circ} \mathrm{W}$, rather than over the La Plata Basin.

In summary, the UCLA AGCM forced with the mean SST of the post79 La Niña events effectively simulates the precipitation anomalies over tropical regions. The model also reproduces well the upperlevel atmospheric circulation anomalies in the $\mathrm{SH}$, particularly around South America, where it succeeds in reproducing the spatial structure but underestimates the amplitude over SESA. The model also reproduces southward anomalies of the low-level meridional wind over South America; in this case, the underestimation is greater than that found in the upper-level circulation. Considering these findings, we believe that the model is valuable for studying upper-level anomalies and the related tropicalextratropical teleconnections.

\subsection{Pre 1979 La Niña events}

Considering its effectiveness described in the preceding section, the UCLA AGCM is useful for simulating pre79 La Niña events, particularly upperlevel circulation anomalies. We performed simulations 

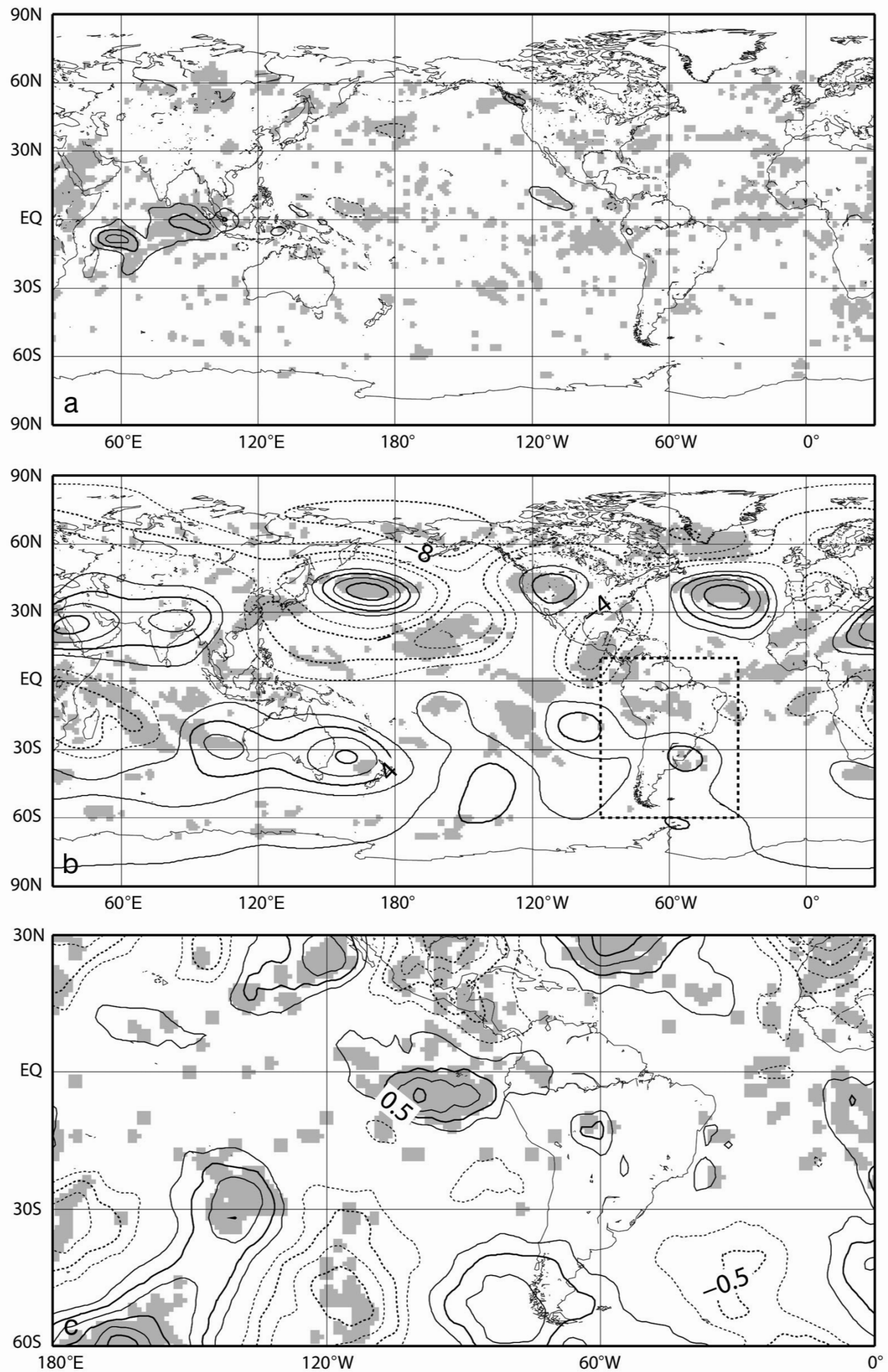

Fig. 7. As in Fig. 5, but for the GOGA-post 1979 minus the GOGA-pre 1979 experiments 


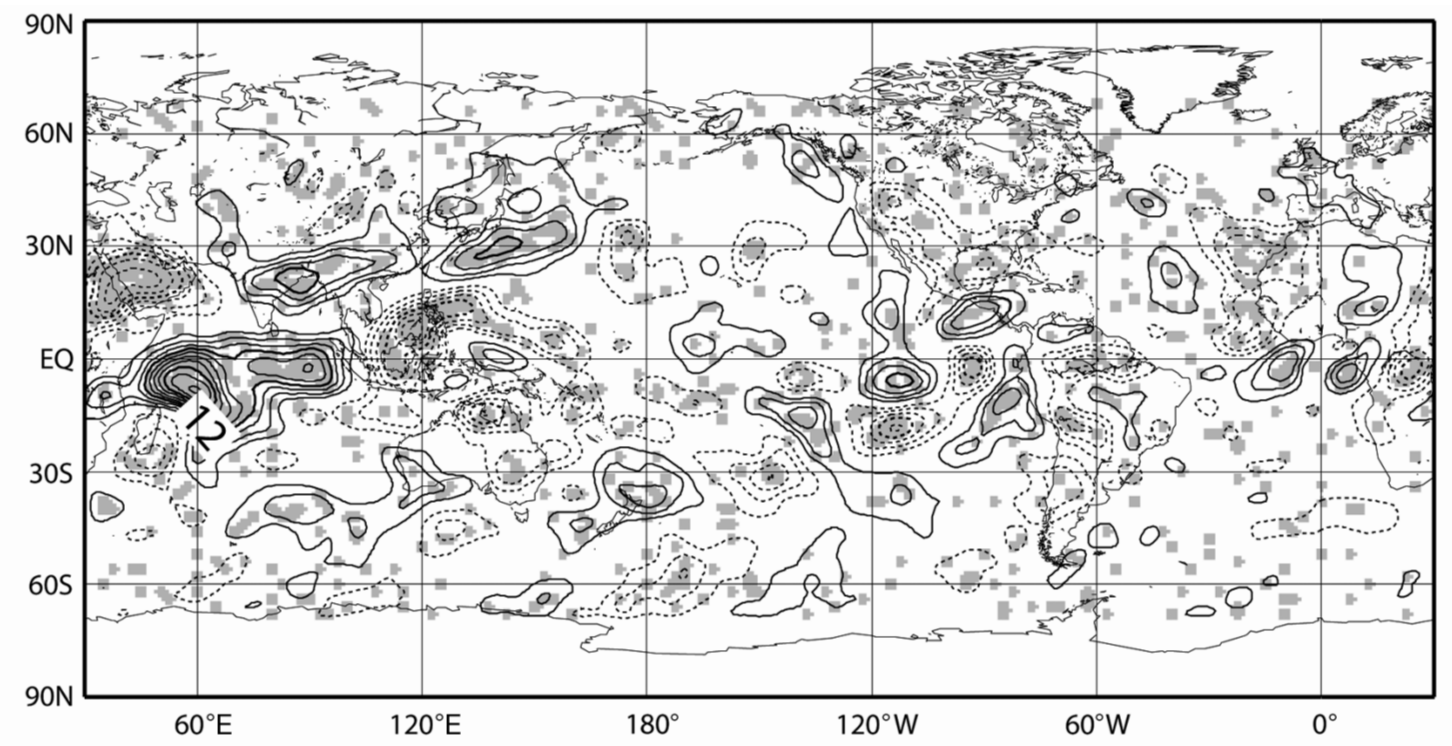

Fig. 8. GOGA-post 1979 minus GOGA-pre 1979 in DJF for $200 \mathrm{hPa}$ divergence; the contour interval is $3 \times 10^{-7} \mathrm{~s}^{-1}$. Areas statistically significant at the $95 \%$ level are shaded. The negative contours are dotted, and the 0 contour is omitted

analogous to those described previously but prescribing monthly averages of the observed SST fields during the La Niña events before 1979 (shown in Fig. 3b); we denote this experiment as GOGA-pre79. We focused on the differences between the GOGApost79 and GOGA-pre79 experiments.

Fig. 7 shows GOGA-post79 minus GOGA-pre79 precipitation, the $200 \mathrm{hPa}$ stream function, and the $850 \mathrm{hPa}$ meridional wind. The greatest differences in precipitation are in the tropical Indian Ocean; these values are positive, statistically significant, and reach $4 \mathrm{~mm} \mathrm{~d}^{-1}$. These precipitation anomalies are associated with important divergence anomalies at $200 \mathrm{hPa}$ over this region (Fig. 8). In the equatorial region, the $200 \mathrm{hPa}$ stream function anomalies (Fig. 7b) indicate westerly anomalies over the western Pacific and easterly anomalies over the western Indian Ocean and Africa. These anomalies are consistent with the solution of Gill (1980) for equatorial heating. Significant anomalies also occur over South America. In particular, we found a cyclonic anomaly centered at approximately $33^{\circ} \mathrm{S}-55^{\circ} \mathrm{W}$, which is consistent with the negative divergence anomalies at the same level over SB-NU (Fig. 8) due to the relationship between divergence and vorticity transport processes, as explained by Robertson \& Mechoso (2000). In the actual atmosphere, the negative divergence anomalies would be consistent with precipitation anomalies of the same sign over SB-NU. This simulation captures the convergence but not the precipitation anomalies, probably because of the poor ability of the model to reproduce precipitation anomalies in this region. Dif- ferences in the $850 \mathrm{hPa}$ meridional wind (Fig. $7 \mathrm{c}$ ) are only statistically significant north of the La Plata Basin.

Next, we show the results of simulations designed to study the role of different oceanic basins on the GOGA post79 minus pre79 differences. We define Indian Ocean-Global Atmosphere, Pacific OceanGlobal Atmosphere, and Atlantic Ocean-Global Atmosphere (IOGA, POGA and AOGA, respectively) post79 and pre79 experiments. The IOGA experiments are analogous to the GOGA experiments, except that we prescribed monthly composites of SST averaged over all La Niña events after or before 1979 only in the region between Asia and $30^{\circ} \mathrm{S}$ and between Africa and $120^{\circ} \mathrm{E}$. Between $30^{\circ}$ and $40^{\circ} \mathrm{S}$ and between $120^{\circ}$ and $130^{\circ} \mathrm{E}$, a linear transition to the 1949-2009 climatology was set, and this climatology is prescribed elsewhere. The POGA experiments are defined in an analogous way; SST corresponding to La Niña events is prescribed between $120^{\circ} \mathrm{E}$ and the Americas and between $30^{\circ} \mathrm{S}$ and $30^{\circ} \mathrm{N}$. The SST fields are relaxed to the 1949-2009 climatology from $120^{\circ}$ to $110^{\circ} \mathrm{E}$, from $30^{\circ}$ to $40^{\circ} \mathrm{S}$ and from $30^{\circ}$ to $40^{\circ} \mathrm{N}$. For the AOGA experiments, the SST corresponding to La Niña events is prescribed between the Americas to the west and Africa and Europe to the east and from $30^{\circ} \mathrm{S}$ to $30^{\circ} \mathrm{N}$, and it is relaxed to the 1949-2009 climatology from $30^{\circ}$ to $40^{\circ} \mathrm{S}$ and from $30^{\circ}$ to $40^{\circ} \mathrm{N}$.

Fig. 9 shows the differences between the IOGApost79 and IOGA-pre79 experiments. The results for precipitation and upper-level circulation have important similarities with those shown in Fig. 7 (GOGA- 

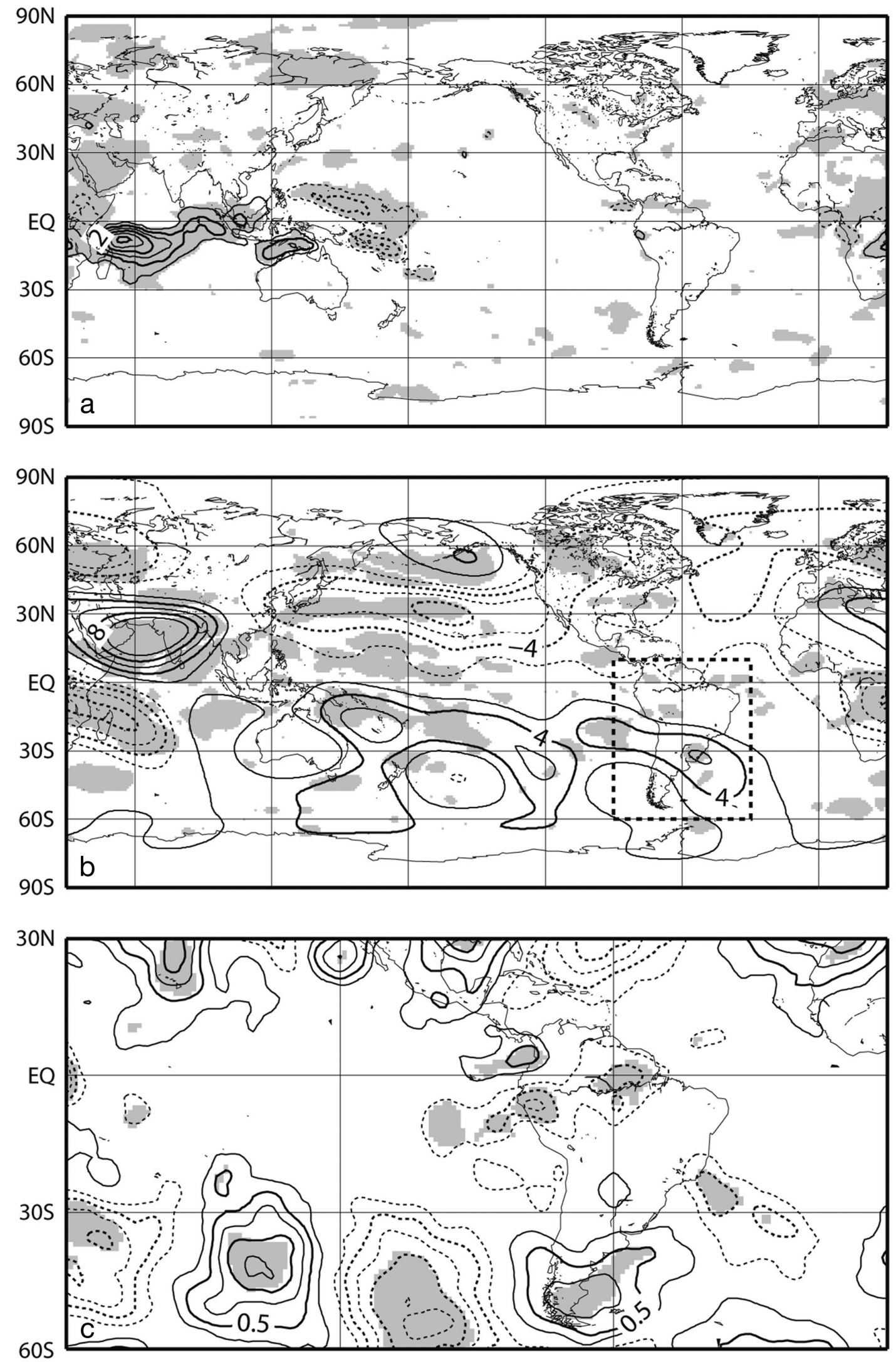

Fig. 9. As in Fig. 8, but for the Indian Ocean-Global Atmosphere (IOGA)-post 1979 minus the IOGA-pre 1979 experiments 
post79 minus GOGA-pre79). In particular, in the same region around South America considered earlier, the pattern correlation of the $200 \mathrm{hPa}$ stream function in GOGA-post79 minus GOGA-pre79 versus the analogous IOGA difference is 0.94 . This suggests that most upper-level atmospheric circulation differences between post79 and pre79 La Niña events in the GOGA experiments are caused by Indian Ocean SST differences. We propose that the mechanism responsible for the effects of these SST differences on atmospheric circulation is barotropic wave dispersion, in a way similar to that found by Drumond \& Ambrizzi (2008) and Chan et al. (2008). It should be noted that the topics of these works are similar but not identical to the object of the IOGA experiment. Drumond \& Ambrizzi (2008) studied SST patterns different than the one considered here, while Chan et al. (2008) obtained similar results to those of the IOGA experiment, but studied a different season. The IOGA-post79 minus -pre79 results do not show significant differences in low-level meridional winds over South America (Fig. 9c).

The differences between POGA-post79 minus POGA-pre79 experiments are shown in Fig. 10. Positive precipitation differences are evident over the western tropical Pacific Ocean, and moderate negative differences over the tropical Indian Ocean (Fig. 10a). There are statistically significant differences in the upper level circulation over large parts of the $\mathrm{SH}$, including the southern Pacific Ocean and South America (Fig. 10b), although they do not help to explain the results of the GOGA experiments. The pattern correlation around South America is only 0.25.

Fig. 11 shows the differences between the AOGA post79 and pre79 simulations. Positive differences in precipitation occur over the equatorial Atlantic Ocean (Fig. 11a). The upper level circulation differences are moderate (Fig. 11b). A region of South America that extends from part of the Amazon Basin to the SB-NU region shows important southerly differences in the meridional $850 \mathrm{hPa}$ wind (Fig. 11c). This difference can be associated with a decrease in the low-level moisture transport towards SB-NU during the post79 La Niña events compared with the pre79 moisture transport. Barreiro \& Tippmann (2008) found through numerical simulations that a warm SST anomaly at the equatorial Atlantic Ocean induces equatorial westerlies and weakens the lowlevel jet that transports moisture from the Amazon to SESA. The results of the AOGA experiment are consistent with this conclusion, and therefore we hypothesize that the warmer SST of the tropical Atlantic Ocean during the post79b La Niña events may help to explain the differences in the impact of La Niña on SB-NU through its effects on the low-level circulation over South America. However, considering that the GOGA experiment shows much weaker differences between post79 and pre79 in terms of the $850 \mathrm{hPa}$ meridional winds, further research on this hypothesis may require improving the ability to simulate lowlevel atmospheric circulation processes over South America.

\section{DISCUSSION AND CONCLUSIONS}

For the period 1979-2009, the correlation between the N3.4 index and simultaneous precipitation over SB-NU during summer increased compared with that of the period 1949-1978, reaching statistically significant values. This result is consistent with the findings of Kayano et al. (2009). Moreover, the lower correlation between N34 and precipitation over SB-NU during the earlier period was caused by a weak connection between La Niña and rainfall over this region. Based on the numerical simulations, we proposed a plausible mechanism that can help explain this change.

La Niña events before and after 1979 have significantly different SST anomalies. However, no important differences occurred in the central equatorial Pacific Ocean. In adjacent tropical regions, particularly in the Atlantic and Indian Oceans, events after 1979 had higher temperatures, such that the differences exceeded $0.5^{\circ} \mathrm{C}$, according to the ERSST data set, v2 (Reynolds et al. 2002).

The cold ENSO episodes of the DJF periods in 1979-2009 were associated with a $200 \mathrm{hPa}$ circulation cyclonic anomaly over SESA and the SACZ; this anomaly was related to lower precipitation over SB$\mathrm{NU}$ and weaker moisture transport from the north (Robertson \& Mechoso 2000). Because the network of observations in the eastern Pacific and South America was very sparse during the greater part of the 19491978 period, the differences between the post79 and pre79 La Niña events were studied through numerical simulations. The SST fields prescribed to these simulations were obtained from the ERSST v2. This data set was selected because it only assimilates in situ observations, in order to avoid bias that may occur if satellite observations are also assimilated, since satellite observations are only available for the most recent decades.

A comparison of numerical simulations that consider global SST fields corresponding to post79 and pre79 La Niña events revealed the most important 

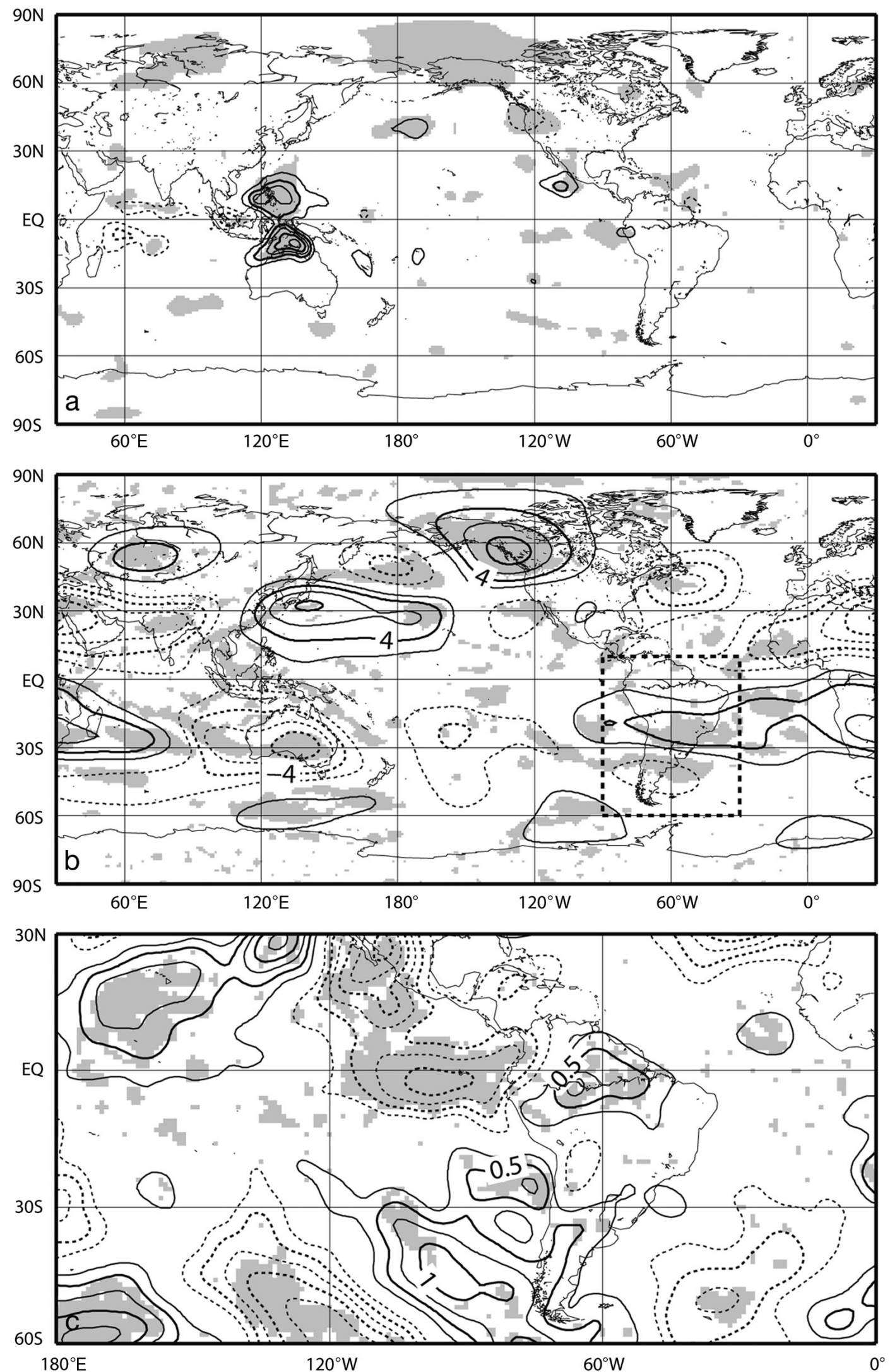

Fig. 10. As in Fig. 8, but for the Pacific Ocean-Global Atmosphere (POGA)-post 1979 minus the POGA-pre 1979 experiments 

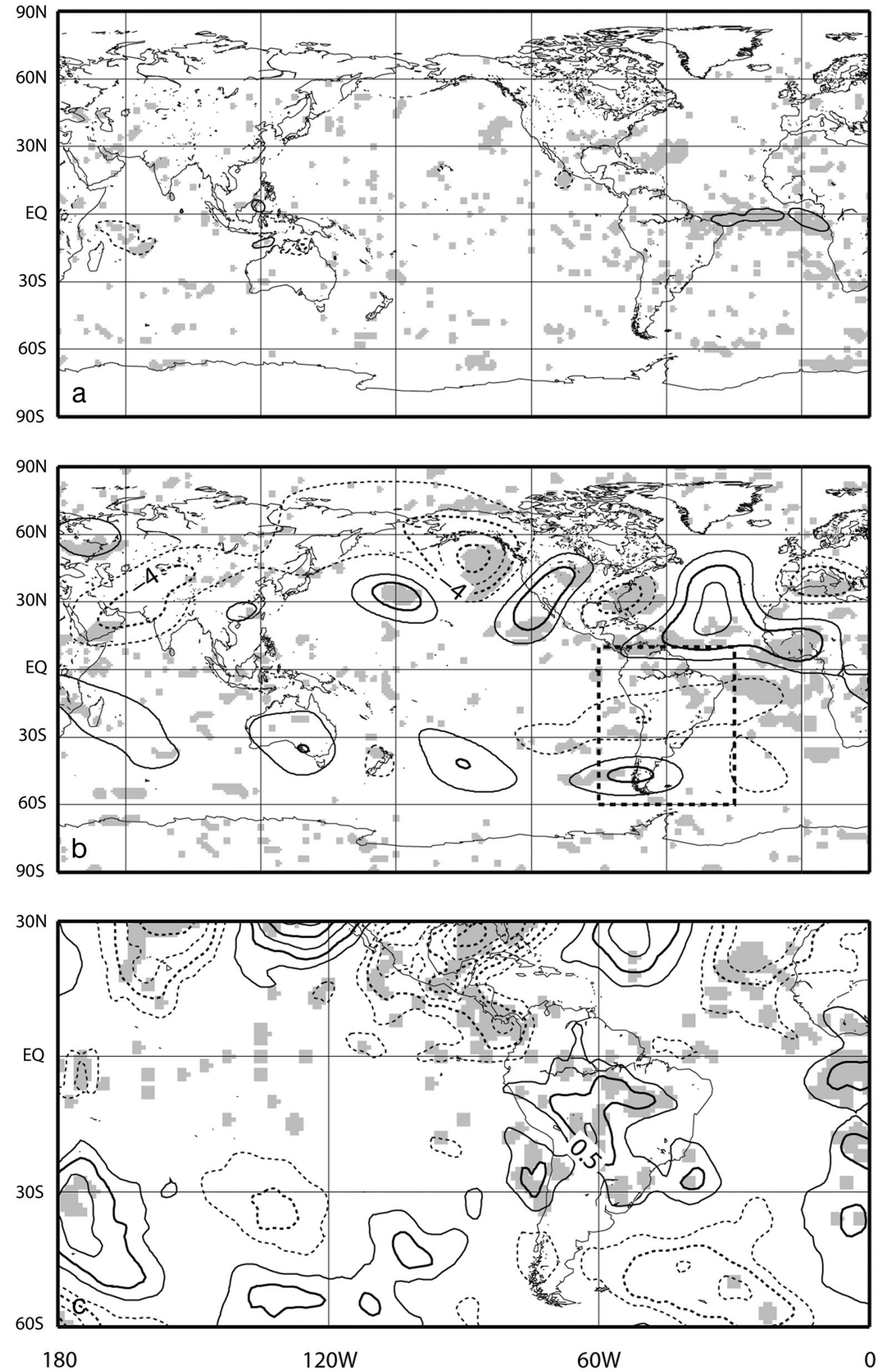

Fig. 11. As in Fig. 8, but for the Atlantic Ocean-Global Ocean (AOGA)-post 1979 minus the AOGA-pre 1979 experiments 
differences in the upper-level circulation: the vorticity difference between the post79 minus pre79 events was cyclonic eastward over SESA, and the corresponding difference in the divergence was negative over SB-NU. This result is consistent with the reduced precipitation over SB-NU during the post79 La Niña events compared with the pre79 events. Therefore, we hypothesized that such circulation differences significantly contribute to the increase in the correlation between the N3.4 index and the regional precipitation in the later period.

Other numerical experiments allow for the separate assessment of the potential influence of various oceanic regions. According to these experiments, the Indian Ocean SST anomalies largely explain the differences in the upper-level circulation between the post79 and pre79 La Niña events across most of the $\mathrm{SH}$ (Figs. $7 \mathrm{~b} \& 9 \mathrm{~b}$ ), particularly in the region of interest. Consequently, we suggest that SST differences over the Indian Ocean greatly contribute to the differences in the La Niña impacts over SB-NU before and after 1979. We propose that the mechanism responsible of the effects of these SST differences on the upper-level circulation is barotropic wave dispersion, in a way similar to that found by Drumond \& Ambrizzi (2008) and Chan et al. (2008). The SST differences over the tropical Atlantic Ocean may also help explain the differences in La Niña impacts on SB-NU before and after 1979 through the effects on the low-level circulation over the tropical Atlantic and South America in ways that are consistent with the mechanisms proposed by Barreiro \& Tippmann (2008). Further research should include the study of processes related to the long-term evolution of global SST patterns related to La Niña (such as long-term global warming or the PDO), and improvements on the simulation of low-level circulation over South America.

Finally, in addition to the Pacific Ocean, other oceanic regions have the potential to moderate the influence of ENSO over the study region; thus, the SST anomalies accounted for within the seasonal climatic forecasts during DJF should be described with $>1$ degree of freedom. Given the sample size of high-quality SST observations, we recommend using numerical circulation models for climatic seasonal forecasts in SB-NU.

Acknowledgements. This research received funding from the European Community's Seventh Framework Programme (FP7/2007-2013) under Grant Agreement no. 212492 (CLARIS LPB - A Europe-South America Network for Climate Change Assessment and Impact Studies in the La Plata
Basin). A fellow member of CLARIS LPB, Dr. Marcelo Barreiro, provided important suggestions that improved this work.

\section{LITERATURE CITED}

Aceituno P (1988) On the functioning of the southern oscillation in the South American sector. I. Surface climate. Mon Weather Rev 116:505-524

Aceituno P (1989) On the functioning of the southern oscillation in the South American sector. II. Upper air circulation. J Clim 2:341-355

Barreiro M, Tippmann A (2008) Atlantic modulation of El Niño influence on summertime rainfall over southeastern South America. Geophys Res Lett 35:L16704, doi: 10.1029/2008GL035019

Barreiro M, Chang P, Saravanan R (2002) Variability of the South Atlantic Convergence Zone as simulated by an atmospheric general circulation model. J Clim 15: 745-763

Barreiro M, Chang P, Saravanan R (2005) Simulated precipitation response to SST forcing and potential predictability in the region of the South Atlantic Convergence Zone. Clim Dyn 24:105-114

Carvalho LMV, Jones C, Silva AE, Liebmann B, Silva Dias PL (2011) The South American Monsoon System and the 1970s climate transition. Int J Climatol 31:1248-1256

Casey KS, Cornillon P (2001) Global and regional sea surface temperature trends. J Clim 14:3801-3818

Cattell RB (1966) The scree test for the number of factors. Multivariate Behav Res 1:245-276

> Cazes-Boezio G, Robertson AW, Mechoso CR (2003) Seasonal dependence of ENSO teleconnections over South America and relationships with precipitation in Uruguay. J Clim 16:1159-1176

Chan SC, Behera SK, Yamagata T (2008) Indian Ocean Dipole influence on South American rainfall. Geophys Res Lett 35:L14S12, doi: 10.102/2008GL034204

> Chen M, Xie P, Janowiak JE, Arkin PA (2002) Global land precipitation: a 50-yr monthly analysis based on gauge observations. J Hydrometeorol 3:249-266

> Drumond AR, Ambrizzi T (2008) The role of the South Indian and Pacific oceans in South American monsoon variability. Theor Appl Climatol 94:125-137

> Farrara JD, Mechoso CR, Robertson AW (2000) Ensembles of AGCM two-tier predictions and simulations of the circulation anomalies during winter 1997-98. Mon Weather Rev 128:3589-3604

Gill AE (1980) Some simple solutions for heat-induced tropical circulation. QJR Meteorol Soc 106:447-462

- Grimm AM (2003) The El Niño impact on the Summer Monsoon in Brazil: regional processes versus remote influences. J Clim 16:263-280

> Grimm AM, Silva Dias PL (1995) Analysis of tropicalextratropical interactions with influence functions of a barotropic model. J Atmos Sci 52:3538-3555

Grimm AM, Zilli TM (2009) Interannual variability and seasonal evolution of summer monsoon rainfall in South America. J Clim 22:2257-2275

> Grimm AM, Ferraz SET, Gomes J (1998) Precipitation anomalies in Southern Brazil associated with El Niño and La Niña events. J Clim 11:2863-2880

- Grimm AM, Barros VR, Doyle ME (2000) Climate variability in southern South America associated with El Niño and 
La Niña events. J Clim 13:35-58

Grimm AM, Pal JS, Giorgi F (2007) Connection between spring conditions and peak summer monsoon rainfall in South America: role of soil moisture, surface temperature, and topography in eastern Brazil. J Clim 20:5929-5945

Kalnay E, Mo KC, Paegle J (1986) Large-amplitude, shortscale stationary Rossby waves in the Southern Hemisphere: observations and mechanistic experiments to determine their origin. J Atmos Sci 43:252-275

Kalnay E, Kanamitsu M, Kistler R, Collins W and others (1996) The NCEP/NCAR 40-year reanalysis project. Bull Am Meteorol Soc 77:437-471

Kayano MT, De Oliveira CP, Andreoli RV (2008) Interannual relations between South American rainfall and tropical sea surface temperature anomalies before and after 1976. Int J Climatol 29:1439-1448

Konor CS, Cazes Boezio GC, Mechoso CR, Arakawa A (2009) Parameterization of PBL processes in an atmospheric general circulation model: description and preliminary assessment. Mon Weather Rev 137:1061-1082

Kousky VE, Kayano MT (1994) Principal modes of outgoing longwave radiation and 250-mb circulation for the South American sector. J Clim 7:1131-1143

Liebmann B, Kiladis GN, Vera CS, Saulo C, Carvalho L (2004) Subseasonal variations of rainfall in South America in the vicinity of the low-level jet east of the Andes and comparison to those in the South Atlantic Convergence Zone. J Clim 17:3829-3842

Mo KC, Ghil M (1987) Statistical dynamics of persistent anomalies. J Atmos Sci 44:877-901

Murphy AH, Epstein ES (1989) Skill scores and correlation coefficients in model verification. Mon Weather Rev 117: $572-581$

Nogués-Paegle J, Mo KC (1997) Alternating wet and dry conditions over South America during summer. Mon Weather Rev 125:279-291

Oort AH (1983) Global atmospheric circulation statistics, 1958-1973. NOAA Prof Pap 14. NOAA, Rockville, MD

Paegle JN, Mo KC (2002) Linkages between summer rainfall variability over South America and sea surface temperature anomalies. J Clim 15:1389-1407

Pisciottano G, Díaz A, Cazess G, Mechoso CR (1994) El Niño-Southern oscillation impact on rainfall in Uruguay. J Clim 7:1286-1302

Poveda G, Mesa OJ (1997) Feedbacks between hydrological processes in tropical South America and large-scale ocean-atmospheric phenomena. J Clim 10:2690-2702

Reynolds RW, Rayner NA, Smith TM, Stokes DC, Wang W

Editorial responsibility: Andrea Carril,

Buenos Aires, Argentina (Guest Editor)
(2002) An improved in situ and satellite SST analysis for climate. J Clim 15:1609-1625

Robertson AW, Mechoso CR (2000) Interannual and interdecadal variability of the south Atlantic convergence Zone. Mon Weather Rev 128:2947-2957

Robertson AW, Farrara JD, Mechoso CR (2003) Simulations of the atmospheric response to South Atlantic sea surface temperature anomalies. J Clim 16:2540-2551

Ropelewski CF, Halpert MS (1987) Global and regional scale precipitation patterns associated with the El Niño/ Southern Oscillation. Mon Weather Rev 115:1606-1626

> Ropelewski CF, Halpert MS (1989) Precipitation patterns associated with the high index phase of the Southern Oscillation. J Clim 2:268-284

$>$ Saji NH, Ambrizzi T, Ferraz SET (2005) Indian Ocean Dipole mode events and austral surface air temperature anomalies. Dyn Atmos Oceans 39:87-101

Salio P, Nicolini M, Saulo AC (2002) Chaco low-level jet events characterization during the austral summer season. J Geophys Res 107:4816

Sardeshmukh PD, Hoskins BJ (1988) The generation of global rotational flow by steady idealized tropical divergence. J Atmos Sci 45:1228-1251

Silva GAM, Ambrizzi T, Marengo JA (2009) Observational evidences on the modulation of the South American low level jet east of the Andes according the ENSO variability. Ann Geophys 27:645-657

> Taschetto AS, Ambrizzi T (2012) Can Indian Ocean SST anomalies influence South American rainfall? Clim Dyn 38:1615-1628

Trenberth KE (1997) A definition of El Niño. Bull Am Meteorol Soc 78:2711-2777

> Trenberth KE, Caron JM, Stepaniak DP, Worley S (2002) Evolution of El Niño-Southern oscillation and global atmospheric surface temperatures. J Geophys Res 107: 4065

Wang C (2004) ENSO, Atlantic climate variability, and the Walker and Hadley Circulations. In: Diaz H, Bradley R (eds) The Hadley Circulation: present, past and future. Springer, New York, NY, p 173-202

- Xie P, Arkin PA (1997) Global precipitation: a 17-year monthly analysis based on gauge observations, satellite estimates, and numerical model outputs. Bull Am Meteorol Soc 78:2539-2558

Zamboni L, Mechoso CR, Kucharski F (2010) Relationships between upper-level circulation over South America and rainfall over southeastern South America: a physical base for seasonal predictions. J Clim 23:3300-3315

Submitted: March 18, 2015; Accepted: October 30, 2015

Proofs received from author(s): February 8, 2016 